DOI: https://doi.org/10.46502/issn.2710-995X/2020.4.05

\title{
Índice IDEB e proficiência em português e matemática: uma análise sobre o desempenho dos alunos da escola estadual padre Ângelo Biraghi em Macapá
}

\begin{abstract}
IDEB Index and Proficiency in Portuguese and Mathematics: an analysis on the performance of students at the Padre Ângelo Biraghi State School in the city of Macapá
\end{abstract}

\section{Resumo}

Este estudo apresenta resultados de uma investigação sobre a questão da avaliação da qualidade da educação por meio do Índice de Desenvolvimento da Educação Básica IDEB que envolve a proficiência em Português e em Matemática, que são parâmetros para análise do desempenho escolar de alunos da rede pública, além, da apresentação da concepção de alguns autores em relação à avaliação da Educação Básica. Assim, o objetivo deste estudo foi o de analisar a evolução do desempenho escolar dos alunos da Escola Padre Ângelo Biraghi, da rede pública estadual, de Ensino Fundamental com base na proficiência em Português e Matemática, bem como no índice IDEB. Como Metodologia foi proposto uma investigação de abordagem quantitativa com dados coletados no site do INEP, tendo como referência os índices IDEB e desempenho escolar dos estudantes nas áreas de Português e Matemática da Prova Saeb. Como resultado se verifica que em 2017 os alunos obtiveram 29\% de proficiência em Português e 18\% de proficiência em Matemática com índice IDEB de 3,5. Como conclusão observa-se que é necessário a escola juntar esforços para melhorar a proficiência dos alunos tanto em Português quanto em Matemática, observando fatores qualitativos que interferem no desempenho dos alunos, melhorando assim a nota do IDEB.

Palavras-chave: IDEB. Proficiência. Português. Matemática. Avaliação.

\section{Abstract}

This article deals with the question of the evaluation of the quality of education through the Basic Education Development Index (IDEB), which involves Portuguese and Mathematics proficiency, which are parameters for the analysis of the school performance of students in the public network, besides the presentation of the conception of some authors regarding the evaluation of Basic Education. Thus, the objective of this study was to analyze the evolution of the school performance of the students of the Padre Ângelo

\footnotetext{
${ }^{13}$ Mestre em Educação. Técnica em Educação da Secretaria de Educação do Estado do Amapá, Brazil.
} 
Biraghi School, of the state public network, of Elementary School based on proficiency in Portuguese and Mathematics, as well as in the IDEB index. As methodology was proposed a quantitative approach with data collected on the INEP website, with reference to IDEB indexes and student performance in the Portuguese and Mathematics subjects of the Saeb Test. As a result it is verified that in 2015 the students obtained $29 \%$ of Portuguese proficiency and $18 \%$ of proficiency in Mathematics with IDEB index of 3.5. As a conclusion, it is necessary that the school combine efforts to improve students 'proficiency in both Portuguese and Mathematics, observing qualitative factors that interfere in students' performance, thus improving the grade of IDEB.

Keywords: IDEB. Proficiency. Portuguese. Mathematics. Evaluation.

\section{Introdução}

Com a entrada em vigor da $1^{a}$ Lei de Diretrizes e Bases da Educação- LDB em 1961, o governo brasileiro vem, progressivamente, elaborando políticas educacionais que buscam elevar a qualidade da Educação Básica no Brasil onde todos, independente de classe social, pudessem ter acesso a escola pública e gratuita. No entanto somente a partir da Constituição de 1988 a educação ganhou pontos de altíssima importância, destacando-a como universal (direito de todos), gratuita, comunitária e de elevado padrão de qualidade culminando com a promulgação da Lei 9394 de 1996.

Nesse sentido, diversos sistemas avaliativos foram implementados em todas as esferas de governo, destacando-se o Índice de Desenvolvimento da Educação Básica -IDEB, que foi implementado em 2005 pelo Instituto Nacional de Estudos e Pesquisas Educacionais Anísio Teixeira - INEP, cujo objetivo é mostrar os avanços do Ensino Fundamental e Médio das escolas públicas e privadas de todo Brasil, que combina o resultado da Prova Brasil com as taxas de aprovações dos alunos nas escolas, gerando o índice IDEB.

Nesta direção, o objetivo deste estudo foi o de analisar a evolução do desempenho escolar dos alunos da Escola Padre Ângelo Biraghi, da rede pública estadual de Ensino Fundamental com base na proficiência em Português e Matemática, que são elementos base para compor o IDEB.

A justificativa desta pesquisa se fundamenta no fato de que os estudos sobre desempenho escolar e avaliação da Educação Básica são um marco na história recente da educação brasileira, por meio delas é possível conhecer como a estrutura da educação influencia o conhecimento de nossos alunos e, a partir de estudos diagnósticos, é possível formular políticas públicas que objetivem melhorar as condições de aprendizagem dos alunos e com isso evoluir positivamente com os índices que medem a qualidade de ensino da Educação Básica.

Em termos locais, o estudo das taxas de rendimento em Português e Matemática da Escola Padre Ângelo Biraghi são justificáveis pelo fato de que, na referida escola não existe nenhuma ação com foco nesses dados, ou seja, a escola dispõe de uma informação muito importante, mas não os utilizam de forma interna para discutir melhorias locais com vistas 
ao ensino de qualidade dos alunos, daí a necessidade de realizar estudos em nível escolar e discutir os resultados com a comunidade.

\section{Marco Teórico}

\section{O IDEB e a Proficiência em Português e Matemática}

A Constituição Federal de 1988 em seu artigo 205 estende a cobertura da educação como direito universal de todos "A educação, direito de todos e dever do Estado e da família, será promovida e incentivada com a colaboração da sociedade, visando ao pleno desenvolvimento da pessoa, seu preparo para o exercício da cidadania e sua qualificação para o trabalho" (Constituição Federal, 1988, p. 123), e a partir da Carta Magna, o processo de fortalecimento e expansão da educação no Brasil vem ocorrendo de forma gradual e com consideráveis avanços, conforme indica Paz (2009):

Principalmente durante a década de 90, a partir do governo de Fernando Henrique Cardoso, diversas implantações de mudanças legais foram definitivas para $o$ fortalecimento do sistema nacional de avaliação, em especial, a promulgação da LDB n ${ }^{\circ}$ 9394/96, o financiamento da educação por meio da Lei $n^{\circ} 9424 / 96$, que regulamentou o Fundo de Manutenção e Desenvolvimento do Ensino Fundamental e de Valorização do Magistério (FUNDEF), a criação dos Parâmetros Curriculares Nacionais, a municipalização do ensino e o forte apelo da racionalidade técnica para equacionar os problemas educacionais (p. 04).

Por conseguinte, a promulgação da Lei de Diretrizes e Bases de 1996, documento Base da Educação Nacional, reforça a incumbência do poder executivo de fazer levantamento censitário da educação básica em seu artigo 9 "Estabelece as diretrizes da educação básica incumbe à União realizar a coleta do Censo Escolar. Coletar, analisar e disseminar informações sobre a educação" (Lei 9394, 1996, p. 20), além da coleta do censo escolar, o processo de avaliação da educação também está previsto na Lei, conforme indica seu artigo $9^{\circ}$, inciso VI:

[...] VI - assegurar processo nacional de avaliação do rendimento escolar no ensino fundamental, médio e superior, em colaboração com os sistemas de ensino, objetivando a definição de prioridades e a melhoria da qualidade do ensino (Lei 9394, 1996, p. 20).

Nessa perspectiva, o Governo Federal através do Ministério da Educação, implementou em 2007 o Plano de Desenvolvimento da Educação - PDE, com o objetivo de melhorar a educação do país, tem como principal referência o plano de metas do Compromisso de Todos Pela Educação, assinado em 2006, "é a conjugação dos esforços da União, Estados, Distrito Federal e Municípios, em regime de colaboração, das famílias e da comunidade, em proveito da melhoria da qualidade da educação básica" (Lei 9394, 2007, p. 01).

Estados e municípios que fizerem adesão ao compromisso com o plano, seguirão 28 diretrizes pautadas nos diagnósticos de avaliação, um dos eixos do PDE é o IDEB, Índice de Desenvolvimento da Educação Básica, criado em 2005 e implementado em 2007, é um indicador da qualidade da educação que é calculado com base em duas variáveis: a 
nota média dos alunos das provas de proficiência de Português e Matemática e taxas de fluxo escolar como aprovação, reprovação e evasão.

O IDEB é o indicador objetivo para a verificação do cumprimento das metas fixadas no Termo de Adesão ao Compromisso Todos pela Educação, eixo do Plano de Desenvolvimento da Educação, do Ministério da Educação, que trata da educação básica. Nesse âmbito que se enquadra a ideia das metas intermediárias para o Ideb. A lógica é a de que para que o Brasil chegue à média 6,0 em 2021, período estipulado tendo como base a simbologia do bicentenário da Independência em 2022, cada sistema deve evoluir segundo pontos de partida distintos, e com esforço maior daqueles que partem em pior situação, com um objetivo implícito de redução da desigualdade educacional (Fernandes, 2015, p. 01).

Para Saviani (2009) a educação de qualidade emerge de um conjunto de distorções, na qual é diagnosticada pelo IDEB e constituem uma força homogeneizadora que tem por objetivo reforçar os laços coletivos, de todos os indivíduos que compõem a comunidade escolar. Dessa maneira a educação objetiva a sociedade mais igualitária, porém, para isso precisam-se corrigir as distorções políticas, econômicas, administrativas e de valorização dos agentes educativos, pois todo esse conjunto fazem parte do ambiente que culminará com o processo de ensino e aprendizagem dos alunos.

\section{Concepções sobre a avaliação da educação}

Segundo Hanushek (2002) mensurar a qualidade da educação é uma tarefa complexa, pois sofre interferência da carga de variáveis a ela associada, entretanto, ela tem sido medida por meio de testes padronizados do rendimento ou desempenho educacional dos alunos, podendo assim mensurar as habilidades dos alunos e desta forma concluir sobre a aprendizagem dos estudantes.

Embora o sistema de avaliação da Educação Básica, o SAEB, seja a metodologia atual concebida pelo INEP para avaliar a qualidade da educação brasileira, muitos pesquisadores discordam desse processo e fundamentam suas linhas de pensamento defendendo um processo amplo de avaliação da educação que leve em conta, além de aspectos cognitivos dos alunos, os aspectos formativos e outras variáveis globais perfazendo assim um processo que diagnostique a verdadeira realidade das pessoas envolvidas no ambiente escolar.

Cabrito (2009) ao criticar a avaliação da educação em processos quantificáveis, compreende que, este processo apenas coloca as escolas em uma ordem de importância da melhor nota para a pior nota, sendo então considerada aquele estabelecimento que oferece a melhor qualidade em educação se obtiver maior índice de alunos aprovados nos exames qualificadores:

A objetividade deste critério, mensurável e quantificável, tem vindo a justificar o debate que se tem vindo a produzir em torno da qualidade em educação, afirmando-se que as escolas oferecem tanto mais qualidade em educação quanto maior for a taxa de aprovação dos seus alunos naqueles exames (Cabrito, 2009, p. 193). 
Segundo Dourado e Oliveira (2009) uma educação de qualidade tem relação não apenas a dados que se refletem em taxas e índices, mas sim a um conjunto de determinantes que influenciam no processo educacional e envolve características macroestruturais e sociais que estão acima de uma prova onde o aluno tenta resolver algumas questões:

Debater tais questões remete à apreensão de um conjunto de determinantes que interferem, nesse processo, no âmbito das relações sociais mais amplas, envolvendo questões macroestruturais, como concentração de renda, desigualdade social, educação como direito, entre outras. Envolve, igualmente, questões concernentes à análise de sistemas e unidades escolares, bem como ao processo de organização e gestão do trabalho escolar, que implica questões como condições de trabalho, processos de gestão da escola, dinâmica curricular, formação e profissionalização docente (Dourado \& Oliveira, 2009, p. 202)

Gadotti (2013) compreende que o fortalecimento de uma educação de qualidade se dá por fatores macros, como a relação entre a Educação Básica e o Ensino Superior, parceria essa tão necessária quanto os investimentos maciços em educação e recursos para a escola pública.

A qualidade da educação precisa ser encarada de forma sistêmica: da creche ao pósdoutorado. O sistema educacional é formado de muitas partes inter-relacionadas, interdependentes e interativas: o que ocorre em uma de las repercute nas outras. A educação só pode melhorar no seu conjunto. "Nenhuma política educacional pode produzir resultados positivos sem uma integração orgânica entre os diversos níveis de ensino, particularmente entre a Educação Básica e o Ensino Superior" (Gadotti, 2013, p. 09)

Nesse contexto, Gatti (2008) ressalta que, uma avaliação eficiente da educação deve ser constituída de aspectos qualitativos e quantitativos sob a ótica sócio-educacional:

Numa perspectiva democrática, a avaliação dirigida a qualquer segmento ou modalidade de ensino, quando intencional e sistemática, pressupõe colocar em evidência as premissas educativas, os valores e contextos de referência em relação aos quais se avalia. Constituise, assim, como um processo de investigação de uma realidade educativa, em que aspectos qualitativos se entrecruzam com os quantitativos, numa dada perspectiva sobre qualidade sócio-educacional. Essa questão de "qualificar" de que tipo de qualidade estáse falando é um dos problemas não enfrentados nos modelos que temos adotado entre nós. Isto leva a comparações inadequadas e a classificações bem problemáticas (Gatti, 2008, p. 07)

Davok (2007) sugere então que uma educação de qualidade está estritamente associada com a qualidade da gestão educacional gerando uma relação entre as mais diversas dimensões como "as dimensões instrumentais (econômica e pedagógica) que são subsumidas pelas dimensões substantivas (política e cultural), dimensões extrínsecas (política e econômica) que são subsumidas pelas dimensões intrínsecas (cultural e pedagógica)" (Davok, 2007, p. 510). Tais relações resultam em quatro critérios de 
avaliação da educação: o da eficiência, eficácia, efetividade e relevância assim definidas por Davok:

A eficiencia "[...] é o critério econômico que revela a capacidade administrativa de produzir o máximo de resultados com o mínimo de recursos, energia e tempo". É um critério de dimensões instrumental e extrínseca. A eficacia "[...] é o critério institucional que revela a capacidade administrativa para alcançar as metas estabelecidas ou os resultados propostos" (p. 46). Esse critério é de dimensão instrumental e preocupa-se com a consecução dos objetivos intrínsecos, vinculados, especificamente, aos aspectos pedagógicos da educação. A efetividade "[...] é o critério político que reflete a capacidade administrativa para satisfazer as demandas concretas feitas pela comunidade externa". É um critério substantivo extrínseco que reflete a capacidade de a educação responder às preocupações, exigências e necessidades da sociedade. A relevância, por sua vez, "[...] é o critério cultural que mede o desempenho administrativo em termos de importância, significação, pertinência e valor". Esse critério é de natureza substantiva e intrínseca e está diretamente relacionado à atuação da educação para a melhoria do desenvolvimento humano e qualidade de vida dos indivíduos e grupos que participam do sistema educacional e da comunidade como um todo (Davok, 2007, p. 510).

Nas ideias de Dourado, Oliveira e Santos (2007) as mudanças sociais provocam também mudanças nos mais diversos segmentos, inclusive a educação, levando países e pensarem seus sistemas educacionais como um sistema complexo e consequentemente a priorizar a educação como mecanismo de desenvolvimento da sociedade, assim a qualidade da educação passa pela implementação de rigorosas políticas de avaliação educacional. Os autores sugerem as seguintes variáveis para a avaliação da educação:

- Nível de sistema: condições de oferta do ensino;

- Nível de escola: gestão e organização do trabalho escolar;

- Nível do professor: formação, profissionalização e ação pedagógica;

- Nível do aluno: acesso, permanência e desempenho escolar

- Nível do espaço social: a dimensão socioeconômica e cultural dos entes envolvidos;

- Nível do Estado: a dimensão dos direitos, das obrigações e das garantias; (Dourado, Oliveira, \& Santos, 2007, p. 16)

Com tais níveis de análise da estrutura educacional, os autores acreditam que é "possível depreender que essas avaliações contribuem para evidenciar a presença significativa de fatores intrínsecos e fatores associados à produção do trabalho escolar e à aprendizagem" (Dourado, Oliveira, \& Santos, 2007, p. 23), levando de fato à uma avaliação da educação coerente e refletindo a verdadeira realidade dos alunos.

Do ponto de vista da avaliação, diferentes rendimentos escolares dos estudantes refletem desigualdades sociais a que estão submetidos e podem ser maximizados ou reduzidos dependendo do processo escolar a que o aluno está submetido (Cunha, 2010), e a escola, sendo um dos maiores agentes de socialização do mundo atual, exerce influência no processo de redução de desigualdades, desse modo, o fracasso escolar não pode ser concebido sem uma reflexão de sua relação com a desigualdade escolar e desigualdade social. 
Se, tal como analisamos, vários argumentos foram mobilizados para explicar por que a origem do fracasso não pode ser dissociada da relação desigualdade escolar/desigualdade social, há que se fazer referência também a um outro aporte teórico que vem refletindo sobre a relação com o saber. A desigualdade social diante e dentro da escola é um fato. As novas tendências em sociologia da educação procuraram pesquisar as interações e a questão do sentido da escola. Há, portanto, convergências entre as teorias interacionistas e aquelas que colocam o foco em abordagens construtivistas e didáticas (Cunha, 2010, p. 04).

Para Charlot (2007), essa ideia é reforçada pelo fato de que, dentro e fora da escola existe desigualdade de classe, sexo, etnia e de cultura, que se originam em bases materiais e financeiras e também institucionais. Neste caso, a luta contra o fracasso escolar do aluno na verdade é uma luta contra a desigualdade social que permeia o ambiente da sociedade. Assim, as teorias pedagógicas de aprendizagem deveriam incorporar mecanismos que fizessem uso da temática em questão a fim de utilizar o espaço escolar como redutor de desigualdade.

Durkheim compreende que, o espaço escolar é um local de produção de conhecimentos e vivência educacional e, principalmente de socialização dos indivíduos, logo, condena práticas tradicionalistas na escola que encaminhem o aluno à um processo mecânico de aprendizagem, é preciso transformar o aluno em um ser crítico, e combater a desigualdade também é contribuir para o pensamento crítico do aluno (Souza \& Campos, 2016).

Em “Educação, Sua Natureza e Seu Papel”, texto de 1911, Durkheim já refletia que "cada sociedade, considerada num momento determinado de seu desenvolvimento, tem um sistema de educação que se impõe aos indivíduos", evidenciando que, em cada época cada sociedade centraliza um modelo de indivíduo ideal do ponto de vista da moral, do intelectual e físico, e esses modelos são influenciados pela educação (Filloux, 2010). Numa sociedade do consumo a que vivemos, destaca-se o individualismo, pautado pelo capital, as escolas se tornaram um centro de competição e seleção de indivíduos, perpetuando um cruel sistema de exclusão, que gera e patrocina as desigualdades, levando o aluno ao fracasso escolar.

Nesta direção, percebemos que, o pensamento clássico reconhece a escola como um instrumento de segregação de classes, fundamentado nas características do capitalismo moderno, que impõe a educação um perfil meramente selecionador de indivíduos que irão compor uma classe dominante e outros que vão agregar a massa trabalhadora.

A escola então, constitui-se num espaço em que se observa o trânsito dessas desigualdades, onde a meritocracia parece ser bem discreta, dando lugar para os interesses dos grupos dominantes, assim, o aluno pobre, que possui pouco acesso à saúde, nutrição, lazer, também irá se sentir retraído no desenvolvimento escolar, refletindo em queda no rendimento escolar. Daí a importância do papel da avaliação da qualidade da educação no sentido de diagnosticar essas falhas e propor maneiras de reduzir essas desigualdades, refletindo-se em educação de qualidade. 


\section{Metodologia da pesquisa}

Este estudo foi realizado com base em documentos e banco de dados do Inep, logo, se caracteriza como pesquisa bibliográfica e documental, de cunho quantitativo, haja vista que são apresentados os índices IDEB da escola em questão e os níveis de proficiência em Matemática e Português dos alunos que nela frequentam.

A pesquisa quantitativa é definida por Gil (1991) como aquele em que seus resultados se baseiam em números como instrumento de representação da realidade. Faz uso de métodos estatísticos para formalizar o conjunto de dados em que se está trabalhando, podendo ser apenas descritivo ou por meio de rigorosos testes inferenciais para validar os resultados.

Já as pesquisas bibliográfica e documental são definidas por Silva e Menezes (2001, p. 21) como aquelas em que é elaborada "a partir de material já publicado, constituído principalmente de livros, artigos de periódicos e atualmente com material disponibilizado na Internet" (pesquisa bibliográfica) e, "quando elaborada a partir de materiais que não receberam tratamento analítico" (pesquisa documental), sendo então, ambas convenientes ao tipo de estudo que se propõe.

A população de estudo se refere às notas do IDEB e das notas de proficiência dos alunos da Escola Padre Ângelo Biraghi (lócus de investigação) que são coletadas da base de dados do Inep. A amostra foi do tipo "conveniência", haja vista que foram coletadas todas aquelas disponíveis no banco de dados do Inep.

A pesquisa ocorreu no mês de Janeiro de 2021 e, inicialmente foi feito a seleção de materiais que serviram de aporte teórico. Esses materiais versaram sobre a metodologia do Inep para o IDEB, bem como as taxas de proficiências nas disciplinas de Português e Matemática. A seleção dessas duas disciplinas se deu em razão de que somente estas é que são consideradas para o cálculo das proficiências das escolas, assim como ocorre em outros países, inclusive, servindo como parâmetro de comparação com o rendimento de estudantes do exterior.

Em seguida, foram acessados os bancos de dados do Inep para coleta de dados quantitativos acerca do índice do IDEB e dos índices de proficiência na referida escola. Os índices foram organizadas de forma temporal, conforme se encontram no banco de dados do INEP. Após tratamento estatístico descritivo, foi feito uso de gráficos para apresentação dos resultados.

\section{Resultados e discussões}

Com relação às variáveis de estudo desta pesquisa, proficiência em Português e Matemática e índice IDEB, observa-se inicialmente que, o Inep divide o resultado da Prova Brasil nos seguintes níveis: Insuficiente, Básico, Proficiente e Avançado. Essa escala é feita segundo a pontuação na prova e que depende da série em que o aluno está, conforme a tabela a seguir: 
Tabela 1.

Níveis de proficiência segundo as séries.

\begin{tabular}{|c|c|c|c|c|c|c|c|}
\hline \multicolumn{8}{|c|}{ Área } \\
\hline \multicolumn{4}{|c|}{ Português } & \multicolumn{4}{|c|}{ Matemática } \\
\hline \multicolumn{2}{|c|}{$5^{\circ}$ Ano } & \multicolumn{2}{|c|}{$9^{\circ}$ Ano } & \multicolumn{2}{|c|}{$5^{\circ}$ Ano } & \multicolumn{2}{|c|}{$9^{\circ}$ Ano } \\
\hline Nível & Pontos & Nível & Pontos & Nível & Pontos & Nível & Pontos \\
\hline Insuficiente & $0-149$ & Insuficiente & 0-199 & Insuficiente & $0-174$ & Insuficiente & $0-224$ \\
\hline Básico & $150-199$ & Básico & $200-274$ & Básico & $175-224$ & Básico & $225-299$ \\
\hline Proficiente & $200-249$ & Proficiente & $275-324$ & Proficiente & $225-274$ & Proficiente & $300-349$ \\
\hline Avançado & $250 \mathrm{ou}+$ & Avançado & 325 ou + & Avançado & $275 \mathrm{ou}+$ & Avançado & $350 \mathrm{ou}+$ \\
\hline
\end{tabular}

Fonte: Inep

Para este estudo, a análise dos dados concentrou apenas no $5^{\circ}$ ano na referida escola, haja vista que nesta instituição não há Séries Finais. Os anos disponíveis na plataforma de consulta do Inep foram os de 2011, 2013 e 2015. Para a disciplina de Português, os alunos considerados proficientes nesta área (soma das porcentagens dos níveis Avançado + Proficiente) podem ser visualizados no gráfico 1 abaixo:

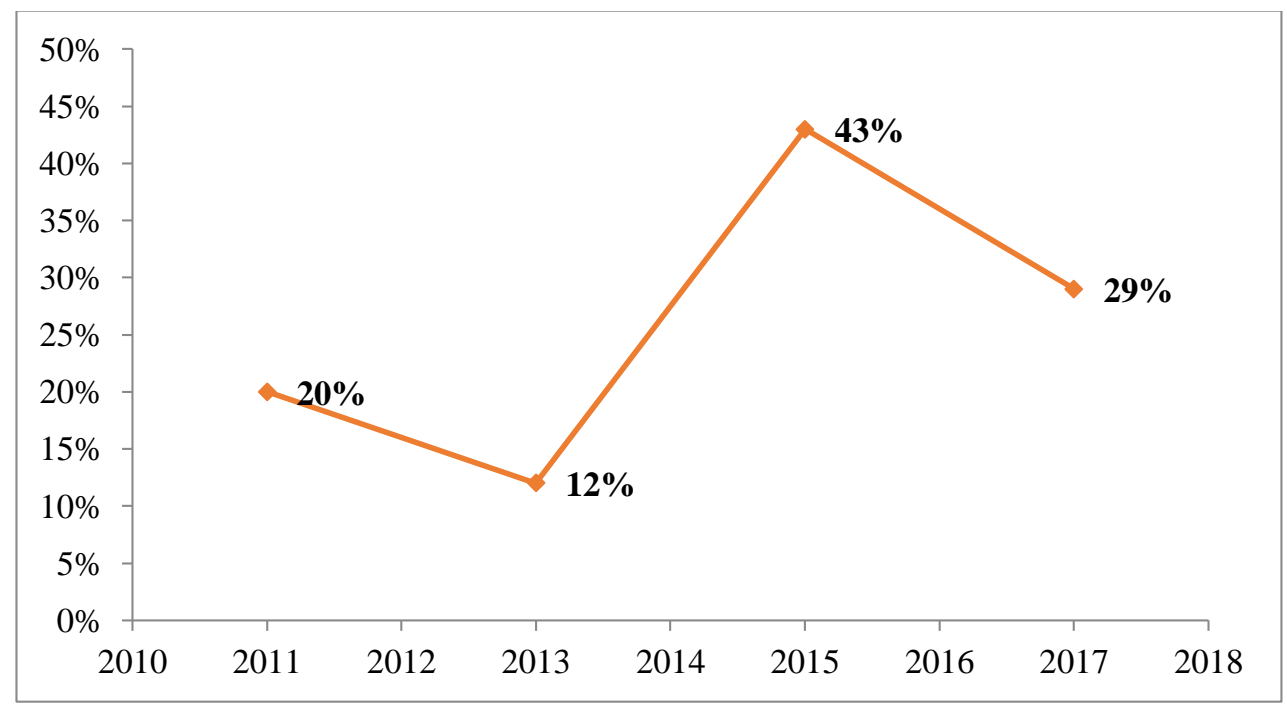

Gráfico 1. Percentual de alunos proficientes em Português, evolução temporal. Fonte: Dados do IDEB

Observa-se no gráfico 2 que, em 2011 havia 20\% de alunos proficientes em Português no $5^{\circ}$ Ano na Escola Padre Ângelo Biraghi, esse número sofreu uma queda para $12 \% \mathrm{em}$ 2013 e subiu consideravelmente em 2015 para $43 \%$ vindo a cair para 29\% em 2017, sendo este o patamar atual de alunos que aprenderam o adequado nesta disciplina. No entanto, verifica-se que em nenhum ano de análise os valores superaram 50\%, ou seja, menos da metade dos alunos desta instituição são proficientes em Português. 
Não foram localizados no banco de dados os fatores que levaram os alunos à considerável queda no índice de proficiência em 2013 (apenas 12\%), assim, uma verificação posterior com uma investigação qualitativa é recomendada nesta instituição para obtenção de dados que justifiquem esse baixo índice ocorrido em 2013.

Uma verificação no banco de dados do Inep permitiu catalogar os índices médios de proficiência dos alunos no Brasil, no Amapá e em Macapá. O índice atual de 29\% de proficiência em Português (2017) pode ser comparado com os índices nacional, estadual e municipal conforme se verifica no gráfico a seguir:

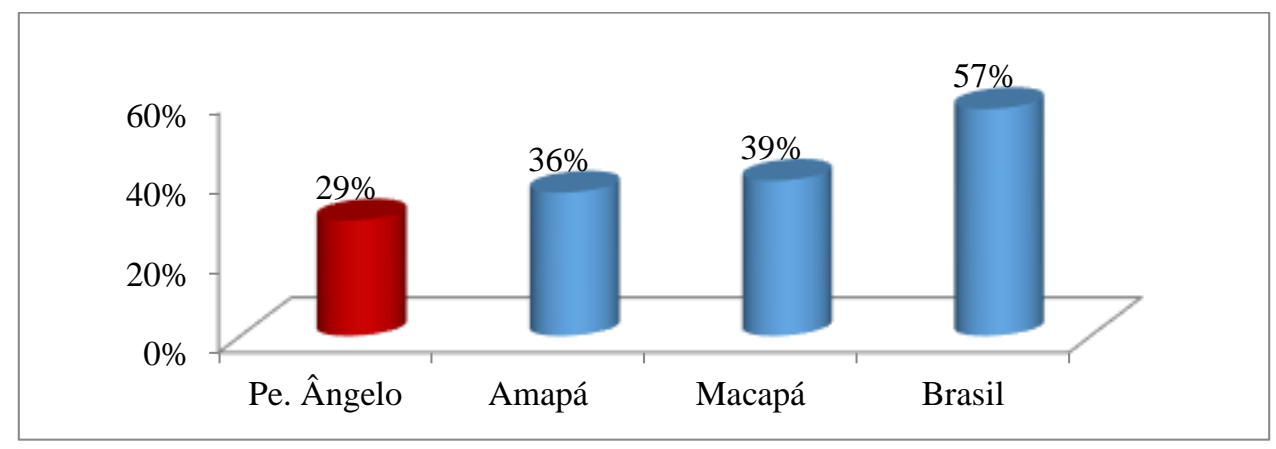

Gráfico 2. Comparativo com os índices nacional, estadual e municipal - Português. Ano de 2017

Fonte: IDEB

Observa-se no gráfico 3 que a proficiência em Português escola Padre Ângelo Biraghi é menor que a média nacional $(57 \%)$ e também menor que a média municipal de Macapá $(39 \%)$ e a média estadual $(36 \%)$

Observando a divisão percentual dos 4 níveis de classificação do Inep, verifica-se que no ano de 2017, os alunos do $5^{\circ}$ Ano em Português obtiveram as seguintes proporções:

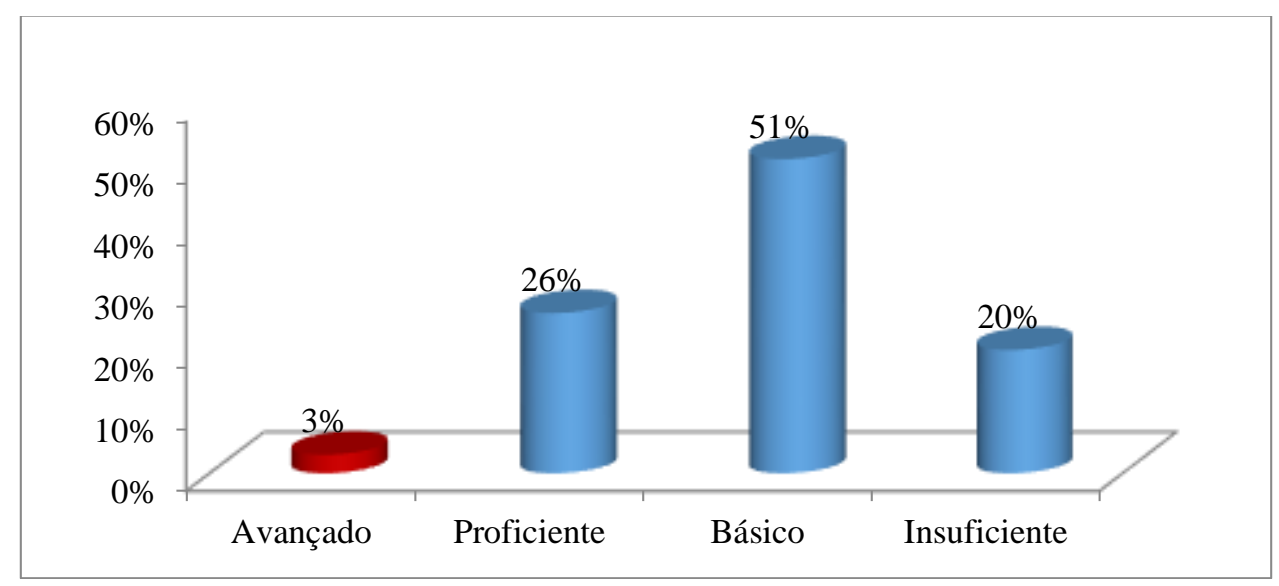

Gráfico 3. Proporção de alunos segundo os níveis do Inep para a aprendizagem em Português.

Fonte: IDEB 
Verifica-se no gráfico 3 que proficiência geral dos alunos vem da soma das variáveis (Avançado + Proficiente) cujos valores são 3\% e 26\%, totalizando 29\%. Observa-se também que, $51 \%$ dos alunos possuem conhecimentos básicos em Português e $20 \%$ possuem conhecimento insuficiente nesta disciplina. Vale ressaltar que no ano anterior, de 2015, 6\% dos alunos estavam classificados como avançados, tendo ocorrido uma queda de $50 \%$ nesse grupo.

Para a disciplina de Matemática a evolução dos alunos considerados proficientes (Avançado + Proficiente) é apresentada no gráfico a seguir:

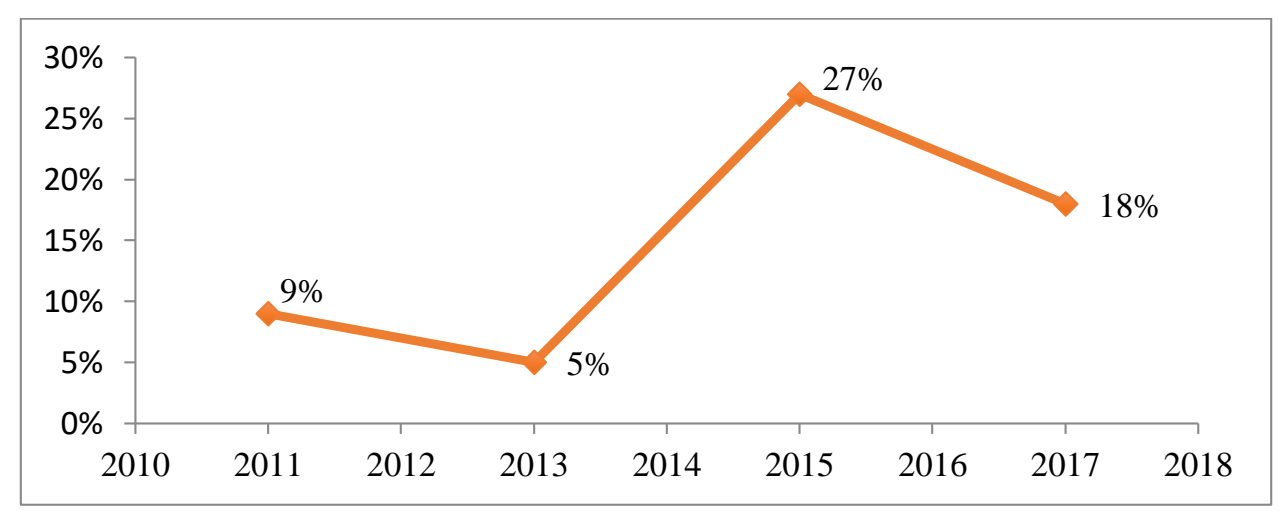

Gráfico 4. Percentual de alunos proficientes em Matemática, evolução temporal. Fonte: IDEB

O gráfico 4 mostra uma evolução temporal de proficiência em Matemática com patamares bem mais abaixo do que na disciplina de Português. Os alunos obtiveram 9\% de proficiência em 2011, caindo para 5\% em 2013 e subindo para $27 \%$ em 2015 e novamente caindo para $18 \%$ em 2017, sendo então um quadro preocupante, pois, aproximadamente para cada 100 alunos, apenas 18 são considerados proficientes nesta disciplina (no ano base de 2017). Também foi possível comparar a proficiência em Matemática com as médias nacional, estadual e municipal:

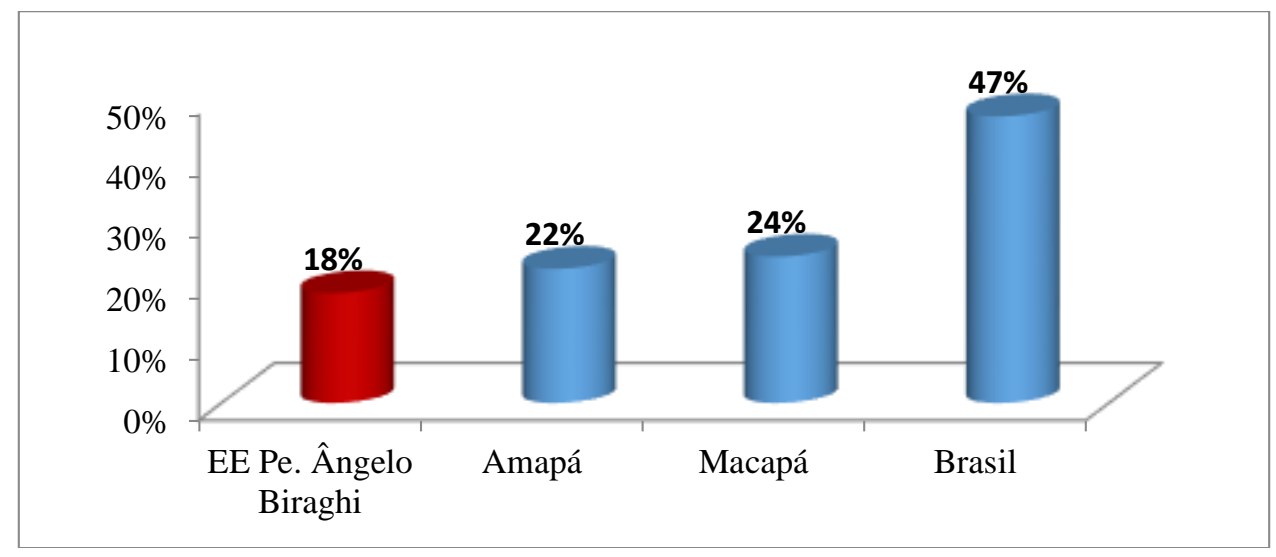

Gráfico 5. Comparativo com os índices nacional, estadual e municipal - Matemática Fonte: Dados do IDEB 


\section{ORANGE JOURNAL}

Tal qual na disciplina de Português, em Matemática os alunos da Escola Padre Ângelo Biraghi estão abaixo da média nacional (47\%) assim como abaixo da média estadual $(22 \%)$ e da média municipal $(24 \%)$.

Observando a divisão percentual dos 4 níveis de classificação do Inep, verifica-se que no ano de 2017, os alunos do $5^{\circ}$ Ano em Matemática obtiveram as seguintes proporções:

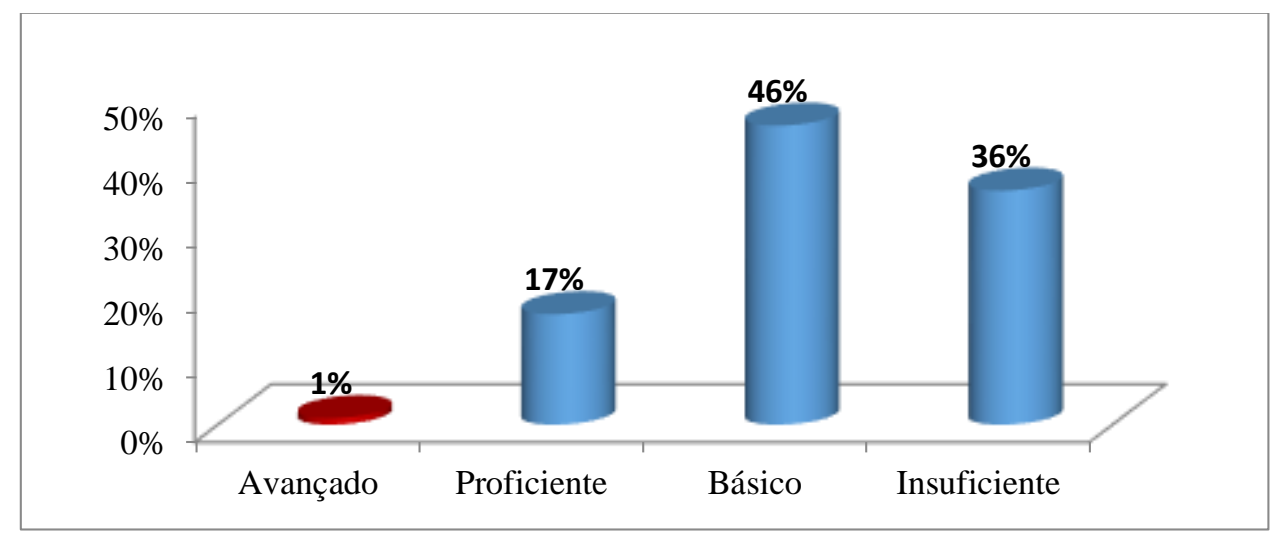

Gráfico 6. Proporção dos alunos segundo o nível do Inep para aprendizado em Matemática.

Fonte: Dados do IDEB

Verifica-se neste gráfico que, apenas 1\% dos alunos em 2017 eram classificados no nível "Avançado", $17 \%$ foram considerados proficientes, $46 \%$ foram classificados como conhecimentos "Básicos" em Matemática e 36\% dos alunos obtiveram desempenho insuficiente nesta disciplina. Em comparação com o ano de 2015, houve redução do número de proficientes e aumento do número de aprendizado insuficiente.

Com relação à evolução do IDEB na Escola Padre Ângelo Biraghi, o gráfico 07 mostra que entre os anos de 2009 e 2017 houve um pico e em seguida uma queda no valor do índice. Após 2017 a escola passou por um processo de encerramento de suas atividades naquela região.

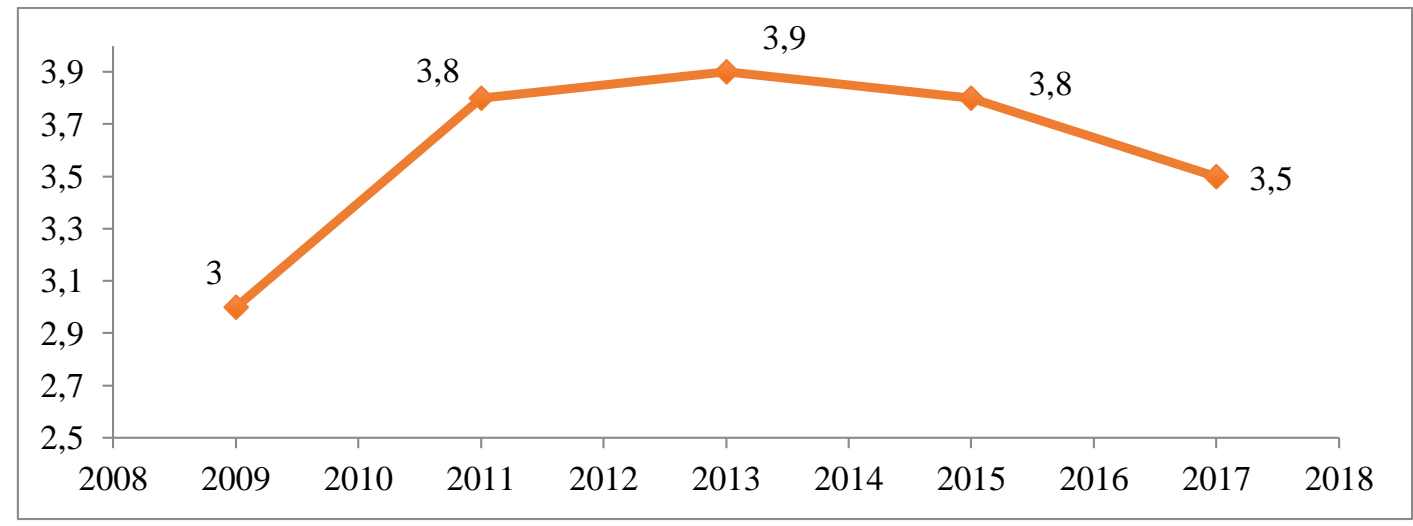

Gráfico 7. Evolução do IDEB na Escola Padre Ângelo Fonte: IDEB 
A meta para 2015 na Escola Padre Ângelo Biraghi era de 3,9 e esta ficou apenas 0,10 abaixo desta meta. Para o ano de 2017 a nova meta estabelecida do IDEB é de 4,1 para esta instituição, porém o IDEB ficou em 3,5 evidenciando considerável queda de rendimento já apontada no gráfico 07 com uma tendência de diminuição nos valores do IDEB para os próximos anos. A escola encerrou suas atividades no ano de 2018 devido baixa matrículas motivadas pelo fato de que no mesmo bairro existiam outras instituições de ensino com maior estrutura e com oferta das mesmas séries.

O alcance e melhoria da meta IDEB é uma condição geral ao Brasil como cumprimento das recomendações do Plano de Desenvolvimento da Educação. Alves (2007) comenta essa importância:

A divulgação do IDEB e a definição de metas para serem cumpridas por estados e municípios até 2022 coloca o tema do efeito composicional novamente em voga. As metas são demandantes, uma vez que estão relacionadas com a superação de dois dos maiores problemas da educação brasileira: elevada taxa de não-promoção e baixo desempenho escolar. Para que o Brasil consiga atingir um IDE igual a 6,0 até 2022, é necessário a quase total regularização do fluxo escolar e que o desempenho das escolas brasileiras melhore sensivelmente (Alves, 2007, p. 17)

Fernandes (2015) salienta que, o estabelecimento da meta nacional do IDEB para 2022 atingir o valor de 6 é em razão de que a qualidade educacional, traduzida nos termos da proficiência e do rendimento escolar estejam nos mesmos patamares de países desenvolvidos participantes da prova do PISA (Programme for Internacional Student Assessment).

Estudo similar foi aplicado por Santini e Fuzinato (2019) onde analisaram o desempenho IDEB de uma escola municipal na cidade de Gurantã do Norte, no Mato Grosso, no período de 2007 a 2017. Os autores relatam aumento do IDEB nesta escola, sempre superior à meta traçada, revelando ótimo desempenho escolar dos alunos. Os autores apontam que alguns dos motivos que podem ter contribuído para o sucesso desta escola foram: aumento do repasse pelo PDDE para as escolas; proporção professor/aluno; e a proporção de docentes efetivos na escola.

Quanto ao repasse do PDDE, enquanto na escola objeto de estudo dos autores Santini e Fuzinato (2019) foi observado aumento anual no repasse financeiro, na escola Padre Ângelo Biraghi não ocorreu este aumento de repasse nessas verbas de custeio, podendo então ser uma justificativa para falta de investimentos em infraestrutura na escola. Os pesquisadores, no entanto, não analisaram a proficiência dos estudantes nas provas de Português e Matemática, elemento fundamental para o cálculo do IDEB.

Nos estudos de Becker (2020) que teve como objetivo discutir sobre a distribuição regional do IDEB no Brasil no período de 2007 a 2017, a autora conclui que existem grandes desigualdades regionais refletindo-se inclusive dentro das próprias regiões como no caso do Norte onde os estados do Amazonas e Rondônia atingiram a meta para 2017 e o Amapá não conseguiu. A autora reflete ainda que, embora o IDEB tenha caminhado 
positivamente nos estado em geral, ainda se faz necessário avançar em políticas públicas com intuito de reduzir as desigualdades regionais e estaduais.

\section{Considerações finais}

Este estudo teve por objetivo analisar a evolução do desempenho escolar dos alunos da Escola Padre Ângelo Biraghi, da rede pública estadual, de Ensino Fundamental com base na proficiência em Português e Matemática. Para alcançar este objetivo foi feito uso da pesquisa quantitativa com coleta de dados no site do Inep.

Foi verificado que para a disciplina de Português, a proficiência dos estudantes em ficou foi de $29 \%$ e para Matemática foi de $18 \%$, sendo que o IDEB para o período considerado variou de 3,0 para 3,5. O valor do IDEB ficou abaixo da meta em todos os anos, e a escola encerrou suas atividades no ano de 2018.

Por meio deste estudo consideramos que, na Escola Padre Ângelo Biraghi, os alunos obtiveram proficiência razoável em Português e muito ruim em Matemática demonstrando a necessidade de adequação no PPP de um projeto que contemple um trabalho específico para estas disciplinas no sentido de futuramente melhorar os índices de proficiência e assim melhorando também o próprio IDEB.

Porém, cabe observar que, na concepção dos autores citados neste estudo, a avaliação da Educação Básica somente representará a realidade dos alunos quando forem incorporados fatores internos e externos à escola, estabelecendo assim uma articulação entre a escola e o meio socioeconômico dos alunos. Conhecer as variáveis qualitativas que influenciam o desempenho do aluno é um procedimento fundamental para poder se medir a verdadeira qualidade educacional.

Por fim, acreditamos ter contribuído com o debate em torno dos processos de avaliação da Educação Básica, e em especial para a Escola Padre Ângelo Biraghi que carece de estudos neste sentido para elevar o nível de excelência da educação fornecida pela escola na comunidade.

\section{Referências}

Alves, F. (2007). Ensaio: Avaliação e Políticas Públicas em Educação. Educação \& Sociedade. Campinas, 15(57), p. 1-19, out./dez 2007.

Becker, K. L. (2020). Qualidade da educação no Brasil: uma análise da distribuição regional do IDEB em 2007 e 2017. Boletim Regional, Urbano e Ambiental, 22. DOI: http://dx.doi.org/10.38116/brua22art15

Constituição Federal. (1988). Disponível em: https://www.planalto.gov.br/ccivil_03/constituicao/constituicao.htm. Acesso em: 01.12 .21

Cabrito, B. G. (2009). Avaliar a qualidade em educação: Avaliar o quê? Avaliar como? Avaliar para que? Cad. Cedes, Campinas, vol. 29, n. 78, p. 178-200.2009 
Charlot, B. (2007). Sucesso escolar: visões e proposições. In: IRELAND, Vera (Coord.). Repensando a escola: um estudo sobre os desafios de aprender, ler e escrever. INEP/UNESCO, p. 22-63

Cunha, M. A. de A. (2010). Sociologia da Educação. - Belo Horizonte: Ed. UFMG. 2010

Davok, D. F. (2007). Qualidade em Educação. Avaliação. Campinas, SP, 12(3), p. $505-513,2007$

Dourado, L. F. \& Oliveira, J. F. (2009). A qualidade da Educação: perspectivas e desafios. Cad. Cedes, Campinas, 29(78), p. 201-215.2009

Dourado, L. F., Oliveira, J. F. de, \& Santos, C. de A. (2007). A qualidade da educação: conceitos e definições. MEC: INEP. Disponível em <http://portal.inep.gov.br/documents/186968/485287/A+qualidade+da+educa\% C3\%A7\%C3\%A3o+conceitos+e+defini\%C3\%A7\%C3\%B5es/ > Acesso em: 08.11 .21

Fernandes, R. (2015). Índice de Desenvolvimento da Educação Básica (Ideb): Metas Intermediárias para a sua Trajetória no Brasil, Estados, Municípios E Escolas. INEP. Disponível em <https://download.inep.gov.br/educacao_basica/portal_ideb/o_que_sao_as_meta s/Artigo_projecoes.pdf > acesso em 10.02.21

Filloux, J. C. (2010). Émile Durkheim. Trad. Maria Lúcia Salles Boudet. - Recife: Fundação Joaquim Nabuco. Ed. Massangana.

Gadotti, M. (2013). Qualidade na Educação: Uma nova abordagem. COEB: Florianópolis.

Gatti, B. A. (2008). Avaliação e Qualidade da Educação. FCC. Disponível em < http://www.diaadiaeducacao.pr.gov.br/portals/seminariopde/documentos/process o5-para_saber_mais_bernadete_gatti.pdf > Acesso em: 08.12.20

Gil, A. C. (1991). Como elaborar Projetos de Pesquisa. 4. Ed. São Paulo: Atlas, 1991

Hanushek, E. (2002). O fracasso das políticas educacionais baseadas em insumos. Stanford, CA: Stanford University, 2002. NBER Working Paper No. 9040.

Lei 6094/2007. Decreto. Dispõe sobre a implementação do Plano de Metas Compromisso Toda pela Educação. 1996. Disponível em: https://www.planalto.gov.br/ccivil_03/Leis/L9394.htm. Acesso em: 01.12.21

Lei 9394/1996. Estabelece as Diretrizes e Bases da Educação Nacional, 2007. Disponível em: https://www.planalto.gov.br/ccivil_03/Leis/L9394.htm. Acesso em: 01.12.21

Paz, F. M da. (2010). O Ideb e a Qualidade da Educação no Ensino Fundamental: Fundamentos, problemas e primeiras Análises comparativas. Revista ETIC, 05(05), 2009. Disponível em: <http://intertemas.toledoprudente.edu.br/index.php/etic/article/view/1953> acesso em: 10.03.21

Santini, G. J., \& Fuzinato, J. M. (2019). Análise do aumento no índice de desenvolvimento da educação básica (ideb) em escola pública municipal de guarantã do norte/mt no período 2007-2017. Debates em Educação, 11(23), 2019. DOI https://doi.org/10.28998/2175-6600.2019v11n23p284-298

Saviani, D. (2009). PDE-Plano Nacional de Educação: Análise crítica da política do MEC. Campinas, SP: Autores Associados, 2009.

Silva, E. L., \& Menezes, E. M. (2001). Metodologia da Pesquisa e Elaboração da Dissertação. $3^{\mathrm{a}}$ Ed. Florianópolis: Laboratório de Ensino à Distância da UFSC, $126 \mathrm{p}$. 2001.

Disponível 


\section{ORANGE JOURNAL}

em:<http://projetos.inf.ufsc.br/arquivos/Metodologia\%20da\%20Pesquisa\%203a $\% 20$ edicao.pdf $>$. Acesso em: 01.12.20

Souza, A. P., \& Campos, N. de. (2016). A concepção de educação de Emile Durkheim e suas interfaces com o ensino. Luminária, 18(02), p. 12-20, 2016 